\title{
Monoclonal Antibody Targeting the HA191/199 Region of H1N1 Influenza Virus Mediates the Damage of Neural Cells
}

\author{
Chun-Yan Guo ${ }^{1,2, a *}$, Qing Feng ${ }^{1,2}$, Li-Ting Yan ${ }^{1,2}$, Xin Xie $^{3}$, Dao-Yan Liang ${ }^{1,2}$, \\ Yan $\mathrm{Li}^{1,2}$, Yang-Meng Feng ${ }^{1,2}$, Li-Jun Sun ${ }^{1,2, b *}$, and Jun $\mathrm{Hu}^{1,2, c *}$ \\ ${ }^{1}$ Central Laboratory of Shaanxi Provincial People's Hospital, Xi'an, Shaanxi 710068, China \\ ${ }^{2}$ Shaanxi Province Research Center of Cell Immunological Engineering and Technology, Xi'an, Shaanxi 710068, China \\ ${ }^{3}$ Key Laboratory of Resource Biology and Biotechnology in Western China, Ministry of Education, \\ College of Life Sciences, Northwest University, Xi'an, Shaanxi 710069, China \\ ${ }^{a} e$-mail: guochunyan101109@126.com \\ ${ }^{b}$ e-mail: lijun200206@163.com \\ ce-mail:78364282@qq.com
}

Received June 29, 2021

Revised September 30, 2021

Accepted September 30, 2021

\begin{abstract}
Vaccination is the most effective mean of preventing influenza virus infections. However, vaccination-induced adverse reactions of the nervous system, the causes of which are unknown, lead to concerns on the safety of influenza A vaccine. In this study, we used flow cytometry, cell ELISA, and immunofluorescence to find that H1-84 monoclonal antibody (mAb) against the191/199 region of the H1N1 influenza virus hemagglutinin (HA) protein binds to neural cells and mediates cell damage. Using molecular simulation software, such as PyMOL and PDB viewer, we demonstrated that the HA191/199 region maintains the overall structure of the HA head. Since the HA191/199 region cannot be removed from the HA structure, it has to be altered via introducing point mutations by site-directed mutagenesis. This will provide an innovative theoretical support for the subsequent modification the influenza A vaccine for increasing its safety.
\end{abstract}

DOI: $10.1134 / \mathrm{S} 0006297921110109$

Keywords: influenza A virus, HA191/199 region, monoclonal antibodies (mAbs), neuronal cell damage

\section{INTRODUCTION}

Influenza A pandemics have been devastating for the human population health and world economy [1]. In the past 100 years, there have been four influenza pandemics that have caused hundreds of millions of infections and tens of millions of deaths [2]. These four influenza pandemics have affected many world regions, so prevention and control of influenza A virus remains both national and global issues.

Currently, vaccination is the best way to prevent and control influenza infection. The vaccine quality is determined by two indicators: protection and safety. Although the use of influenza A vaccine ensures immune protection $[3,4]$, some people suffer from the adverse reactions of the nervous system following vaccination, which raises serious concerns about the vaccine safety. The major adverse reactions include the Guillain-Barre syn-

\footnotetext{
* To whom correspondence should be addressed.
}

drome [5], acute disseminated encephalomyelitis [6], and narcolepsy [7], although death is rare. The reasons for such adverse reactions remain unclear.

It has been reported for nearly a century that many pathogenic microorganisms and their products can mediate disease-related injury through heterophile antigens. Heterophile antigens are antigens of similar nature that are present in human, animal, plant and microbial tissues and are shared by different species. Since the first heterophile antigen was discovered by Forssman, it has become known as the Forssman antigen [8]. According to the literature reports, nucleoprotein of the H1N1 influenza vaccine (Pandemrix vaccine component) and hypocretin receptor 2 antigen have similar fragments leading to the cross-binding of antibodies produced against nucleoprotein in the $\mathrm{H} 1 \mathrm{~N} 1$ influenza vaccine to hypocretin receptor 2, thus causing narcolepsy [9]. The damage caused by the immune cross-recognition of heterophile antigens in microorganisms and human tissues is an important factor in the development of narcolepsy after influenza A vaccination. 
In our previous experiment, we obtained 84 monoclonal antibodies (mAbs) using hemagglutinin (HA) of the H1N1 influenza vaccine as an immunogen. It was found that $\mathrm{H} 1-84 \mathrm{mAb}$ not only recognized a nine-amino acid (a.a). linear epitope 191-LVLWGIHHP-199 of HA, but also cross-bound to the human brain tissue [10, 11]. $\mathrm{H} 1-84 \mathrm{mAb}$ also reacted with heterogeneous nuclear ribonucleoproteins (hnRNPs) A1 and A2/B1 [12], indicating that HA191-LVLWGIHHP-199 and hnRNPA1 and $\mathrm{A} 2 / \mathrm{B} 1$ are heterophile antigens. In theory, H1$84 \mathrm{mAb}$ produced against the influenza virus HA antigen can cross-recognize heterophile antigen hnRNPA1 and A2/B1 and mediate the damage of brain or neural cells. Thus, multiple sclerosis patients produce antibodies against hnRNPA1, which leads to neuronal dysfunction [13]. Therefore, we speculated that H1-84mAb may mediate neuronal cell damage.

Using immunological and bioinformatics methods, as well as, experiments in cells, we demonstrated that $\mathrm{H} 1$ $84 \mathrm{mAb}$ against influenza A virus can mediate neural cell damage. The HA191/199 fragment, to which H1-84mAb binds, is the key region affecting the overall structure of the HA head. We believe that this information will provide innovative theoretical support for the construction of a safe influenza A vaccine.

\section{MATERIALS AND METHODS}

Materials. Human neuroblastoma SHSY5Y cell line and rat primary neuroastrocytes were purchased from the American type culture collection (ATCC). H1-84mAb against the H1N1 influenza virus HA was produced in our laboratory. Fetal calf serum, penicillin, streptomycin, DMEM, and neuroastrocyte culture medium were from Beijing Zhong Shan Jin Qiao Company (China); FOXP3 fixation/permeabilization buffer and fluorescein-labeled goat anti-mouse $\mathrm{IgG}$ were from Life Technologies (USA).

Preparation and identification of mAbs. All animal experiments were approved by the Institutional Animal Care and Use Committee of Shaanxi Provincial People's Hospital (Shaanxi, Xi'an, China). mAbs against the $\mathrm{H} 1 \mathrm{~N} 1$ influenza virus HA protein were produced earlier in our laboratory and titrated with the HA antigen by indirect ELISA [11]. Isotyping of the mAbs was performed with SBAClonotyping TMSystem/HRP isotyping kit according to the manual. mAbs recognizing HA antigenic epitopes were identified by blocking ELISA [10].

Cell culture. Human neuroblastoma SHSY5Y cells stored in liquid nitrogen were plated and cultured in DMEM containing $10 \%$ fetal calf serum, $100 \mathrm{U} / \mathrm{ml}$ penicillin, and $25 \mu \mathrm{g} / \mathrm{ml}$ streptomycin. Neuroastrocytes were cultured in a special medium for this type of cells under the same conditions as SHSY5Y cells. The medium was replaced when the cells grew to $80 \%$ confluency. The experiments were carried out after incubating the cells in a serum-free medium for $24 \mathrm{~h}$.

The binding of $\mathrm{H} 1-84 \mathrm{mAb}$ to neural cells was detected by flow cytometry. Neural cells were cultured for $48 \mathrm{~h}$, trypsinized, and washed with the medium twice. The cells were then incubated with $1 \mathrm{ml}$ of $1 \times$ FOXP3 Perm buffer at room temperature for $30 \mathrm{~min}$ (the neural cells untreated by $1 \times$ FOXP3 Perm buffer were used as controls), washed with PBS three times, and incubated with H1$84 \mathrm{mAb}(1: 100)$ at $37^{\circ} \mathrm{C}$ for $30 \mathrm{~min}$ (isotype antibodies were used as a control). The cells were washed with PBS twice, incubated with fluorescein-labeled goat antimouse $\operatorname{IgG}(1: 200)$ at $37^{\circ} \mathrm{C}$ for $30 \mathrm{~min}$, washed with PBS for three times, and detected by flow cytometry.

Detection of H1-84mAb binding to neurons by immunofluorescence staining. The slides with neural cells were washed with PBS three times, fixed with $4 \%$ paraformaldehyde for $15 \mathrm{~min}$, washed with PBS three times, permeabilized with $0.5 \%$ Triton X-100 at room temperature for $20 \mathrm{~min}$, and washed with PBS three times. Normal goat serum was added to the cells, and the slides were sealed at room temperature for $30 \mathrm{~min}$. The slides were then washed with PBS three times and incubated with $\mathrm{H} 1-84 \mathrm{mAb}$ (dilution, $1: 100$ ) at $37^{\circ} \mathrm{C}$ for $1 \mathrm{~h}$ (isotype antibodies were used as a control), washed with PBS five times, and incubated with the fluorescent secondary antibody (dilution, $1: 200$ ) at $37^{\circ} \mathrm{C}$ for $1 \mathrm{~h}$. The slides were washed with PBS three times, and the stained cells were observed under a fluorescence microscope.

Detection of $41-84 \mathrm{mAb}$ binding to neural cells by cell ELISA. The cells were seeded in a 96-well plate at a density of $1 \times 10^{4}$ cells/well and incubated at $37^{\circ} \mathrm{C}$ overnight. The next day, the wells were washed with PBS three times and the cells were fixed with $10 \%$ formalin $(1: 10$ dilution; $125 \mu \mathrm{l} /$ well) at room temperature for $15 \mathrm{~min}$. The cells were washed with PBST three times, and $150 \mu \mathrm{l}$ of $1 \%$ BSA was added to each well at $37^{\circ} \mathrm{C}$ for $1 \mathrm{~h}$. Next, the cells were incubated with $\mathrm{H} 1-84 \mathrm{mAb}$ for $1 \mathrm{~h} 37^{\circ} \mathrm{C}(\mathrm{H} 1-$ $247 \mathrm{mAb}$ was used as a negative control). After washing three times, $100 \mu \mathrm{l}$ HRP-labelled goat anti-mouse secondary antibody ( $1: 2500$ dilution) was added to each well and the cells were incubated at $37^{\circ} \mathrm{C}$ for $1 \mathrm{~h}$. Next, $100 \mu$ of TMB- $\mathrm{H}_{2} \mathrm{O}_{2}$ chromogenic solution was added to each well and incubated for $10 \mathrm{~min}$ at $37^{\circ} \mathrm{C}$ in the dark. The reaction was terminated with $2 \mathrm{M} \mathrm{H}_{2} \mathrm{SO}_{4}(50 \mu \mathrm{l} /$ well). The amount of bound antibodies was measured with an ELISA reader from absorbance at $450 \mathrm{~nm}\left(\mathrm{OD}_{450}\right)$ and the ratio between $\mathrm{OD}_{450}$ in the tested samples and negative control was calculated. Samples with the ratio $>2.1$ were considered to react with the antibody.

Treatment of neurons with H1-84mAb. Neural cells were preincubated with $1 \mathrm{ml} 1 \times$ FOXP3 Perm buffer at $37^{\circ}$ for $20 \mathrm{~min}$. The buffer was discarded and $\mathrm{H} 1-84 \mathrm{mAb}$ $(0.5 \mu \mathrm{g} / \mu \mathrm{l})$ was added to the wells $\left(\sim 10^{5}\right.$ cells/well $)$, and cultured at $37^{\circ} \mathrm{C}$ for $24 \mathrm{~h}$. The next day, the neural cells treated with $\mathrm{H} 1-84 \mathrm{mAb}$ were cultured at room tempera- 
ture for $20 \mathrm{~min}$ (isotypic antibodies were used as a control). The culture medium was added to the well to a total volume of $500 \mu \mathrm{l}$.

Computer prediction of HA structural changes after removal of the HA191/199 region. The homologous model was established based on the $\mathrm{X}$-ray crystal structure of the HA protein (PDB: $3 \mathrm{LZG}$ ). The HA sequence protein was $99 \%$ similar to the sequence of the $2009 \mathrm{H} 1 \mathrm{~N} 1$ influenza virus. The position of the 9-mer linear epitope (191-LVLWGIHHP-199) of the H1N1 influenza virus $\mathrm{HA}$ recognized by $\mathrm{H} 1-84 \mathrm{mAb}$ in the HA crystal structure was analyzed with the PyMOL software. Modeller software was used for homologous modeling of the HA antigen with the removed 191/199 region. The MOE software was used for molecular dynamics simulation, in combination with the PyMOL software, to observe changes in the HA structure after removal of the 191/199 region.

\section{RESULTS}

Characterization of anti-H1N1 mAbs. In our previous study, we obtained 84 clones of anti-HA mAbs, most of which inhibited the activity of HA. H1-84mAb was found to bind to the linear epitopes of the HA antigen and to cross-react with human brain tissue [11]. It was used to confirm the presence of the epitope in HA using blocking ELISA assay and was analyzed with the DNAMAN software. The location of the epitope in the HA three-dimensional structure was determined with the PyMOL software. The results showed that it is a 9-mer linear epitope (191LVLWGIHHP-199) located in the HA head region [10].

ELISA confirmed that $\mathrm{H} 1-84 \mathrm{mAb}$ reacted with the influenza virus HA protein (H1-247 antibody was used as an isotype negative control; table). The antibody titers in the ascitic fluid and the reactivity of each $\mathrm{mAb}$ against HA were evaluated by indirect ELISA. The results were expressed as the ratio $(\mathrm{P} / \mathrm{N})$ of the optical density at $450 \mathrm{~nm}$ obtained for the antigen binding with the respective $\mathrm{mAb}$ to the signal obtained for negative control $(\mathrm{Sp} 20 / \mathrm{mAb}) ; \mathrm{P} / \mathrm{N}>2.1$ was the cutoff value for the interaction to be considered positive.

Detection of H1-84mAb binding to neural cells by flow cytometry. The results are presented and analyzed with a single-parameter histogram. As shown in Fig. 1, a and d, M1 was determined based on the comparison with the negative control. As shown in Fig. 1, c and f, H1$84 \mathrm{mAb}$ bound to SHSY5Y cells and primary neuroastrocytes (Fig. 1, b and e is the isotypic control, respectively, showing that isotypic antibody did not bind to neural cells). At the same time, as shown in Fig. S1 in the Supplement, it was found that H1-84mAb did not bind to the neuronal membrane of SHSY5Y cells and rat primary neuroastrocytes.

Detection of H1-84mAb binding to neural cells by immunofluorescence staining. In order to further confirm
Characterization of mAbs

\begin{tabular}{c|c|c|c}
\hline mAb & Ig subtype & Antibody titer & Reactivity with HA \\
\hline H1-84 & IgM & $10^{3}$ & $15.12 \pm 0.12$ \\
H1-247 & IgM & $10^{4}$ & $14.43 \pm 0.05$ \\
\hline
\end{tabular}

the binding of $\mathrm{H} 1-84 \mathrm{mAb}$ to neural cells, we performed immunofluorescence staining to detect the location of $\mathrm{H} 1-84 \mathrm{mAb}$ in the cells. The results showed that H1$84 \mathrm{mAb}$ localized to the cytoplasm of the neural cells (Fig. 2, a and c), while the isotypic antibody (control) did not interact with the cells (Fig. 2, b and d).

Detection of $\mathbf{H 1 - 8 4 m A b}$ binding to neural cells by cell ELISA. The binding of H1-84mAb to neural cells was confirmed by cell ELISA. We found that H1-84mAb bound to the neural cells, while no binding was observed for the isotypic antibody (control) (Fig. 3). Compared with the control, the $\mathrm{OD}_{450}$ ratio for the cells interacting with $\mathrm{H} 1-84 \mathrm{mAb}$ was higher than 2.1.

H1-84mAb damages neuronal cells. SHSY5Y cells and primary neuroastrocytes were treated with $\mathrm{H} 1-$ $84 \mathrm{mAb}$ and the resulting changes were observed using a live-cell workstation. We found that H1-84mAb caused significant changes in the cells (Fig. 4), including cell rupture (Fig. 4, $\mathrm{c}$ and $\mathrm{f}$ ), while the isotypic antibody did not damage the cells (Fig. 4, b and e). Figure 4, a and d showed untreated neuronal cells.

The structure of the HA head changes after removal of 191-LVLWGIHHP-199 (191/199 region). The HA monomer consists of the head and the stem (HA1 and HA2 in Fig. 5a, respectively). Analysis of the HA structure with the PDB viewer and PyMOL software showed that the 9-mer linear epitope HA191-LVLWGIHHP-199 (marked in red in Fig. 5a) recognized by $\mathrm{H} 1-84 \mathrm{mAb}$ is located in the HA head and situated within the $\beta$-sheet structure. Removal of the 191/199 region from the HA head (Fig. 5b) results in the disappearance of one $\alpha$-helix and the multi-strand inverted $\beta$-sheet structure parallel to the HA head (as shown by red arrows), and well as changes in the unordered regions of the HA head (Fig. 5, c and d). As can be seen from the Fig. 6a, in the native protein, the $\mathrm{Sa}$ and $\mathrm{Sb}$ antigenic sites are close to the receptor-binding pocket, $\mathrm{Ca} 1$ and $\mathrm{Ca} 2$ sites are at the subunit interface, and $\mathrm{Cb}$ site is in the vestigial esterase domain. Removal of the 191/199 region alters both the structure and the location of the five antigenic sites (Fig. 6b).

\section{DISCUSSION}

Although adverse effects of vaccination against influenza A virus on the nervous system are rare, they raise the issue of flu vaccine safety. The causes of these 

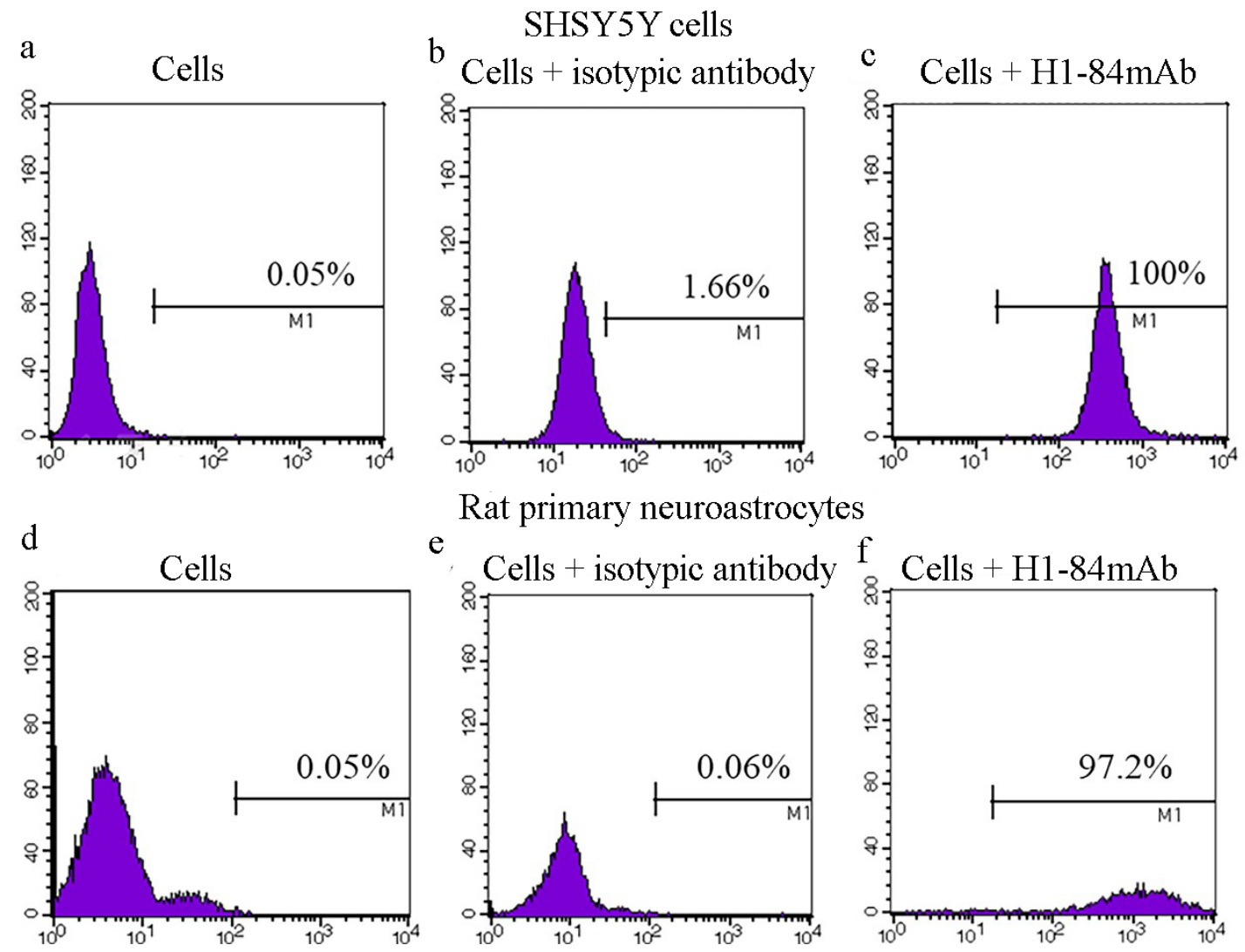

Rat primary neuroastrocytes

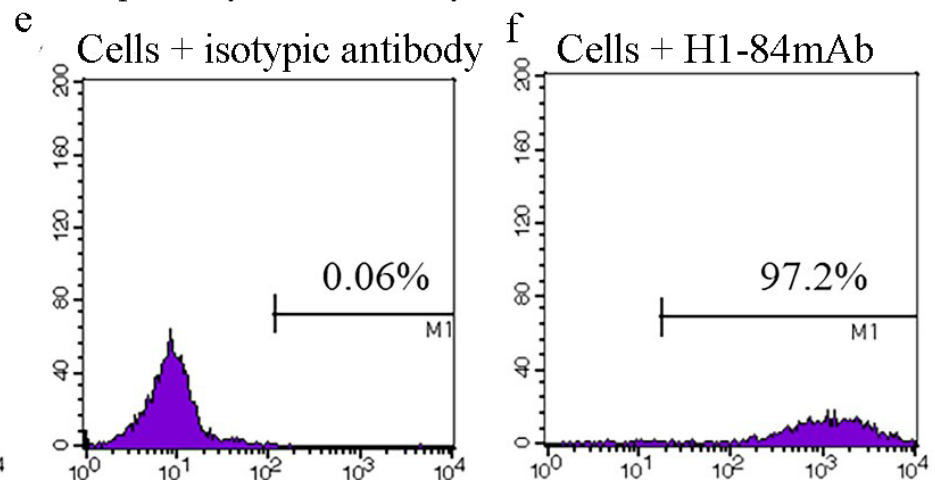

Fig. 1. H1-84mAb cross-binds to neural cells as demonstrated by flow cytometry. Panels (a) and (d), negative control, neural cells in the absence of antibody; b and e, negative control with the isotypic antibody; $c$ and f) H1-84mAb. The cells used were SHSY5Y cells (a-c) and rat primary neuroastrocytes (d-f); $\mathrm{x}$-axis, relative intensity of fluorescence signal or light scattering (channels); $y$-axis, number of cells.

adverse effects are rather complex. Zhou et al. suggested that the damage of the central nervous system is mediated by "the formation of immune complex" [14]. $\mathrm{Ng}$ et al. reported that the influenza virus-induced injury of the central nervous system is promoted by the excessive immune response of the host organism (cytokine storm) [15]. Hallberg et al. suggested that narcolepsy following vaccination against swine influenza A virus (H1N1) is associated with the genes involved in the immunity and neuronal survival [16]. A number of studies have shown that cross-recognition of heterophile antigens plays an important role in the pathogenesis of neurological diseases associated with microbial infection [17]. Earlier, we confirmed that HA191-LVLWGIHHP-199 and hnRNPA1 and hnRNPA2/B1 proteins of the brain tissue are heterophile antigens [10-12] and verified that H1$84 \mathrm{mAb}$ recognized hnRNPA1 and hnRNPA2/B1 in human neuroblastoma SHSY5Y cells and rat primary neuroastrocytes (data to be published). Therefore, H1-84mAb may cross-recognize heterophile antigens hnRNPA1 and A2/B1 and mediate the damage of brain and neural cells, which may be an important factor in the safety of influenza A vaccine. In this study, we first verified the detrimental effect of $\mathrm{H} 1-84 \mathrm{mAb}$ on the cells by demonstrating that
H1-84mAb damages neural cells and causes their death (the study on the damaging effect of H1-84 on the animal nervous system is in progress).

Analysis of protein sequences for the presence of the LVLWGIHHP epitope (BLAST, NCBI) showed that it is absent in human proteins. We believe that the cross-reactivity of $\mathrm{H} 1-84 \mathrm{mAb}$ may be caused by the structural homology between the viral epitope and some human proteins (we will follow this issue in our future research). We collected and purified 12 serum IgG samples from the patients who manifested neurological symptoms after receiving influenza A vaccine. Four samples reacted not only with HA191-LVLWGIHHP-199, but also with the nuclear proteins hnRNPA1 and hnRNPA2/B1. Therefore, the presence of H1-84-like antibodies in the serum of patients demonstrates the importance of heterophile antigens in human diseases (submitted for publication).

In the norm, neuronal hnRNPA1 localizes mainly to the nucleus and can be transported back and forth between the nucleus and the cytoplasm. It was found that the anti-hnRNPAl autoantibodies could induce hnRNPA1 mislocalization, i.e., the massive transfer of hnRNPA1 from the nucleus to the cytoplasm. A portion 


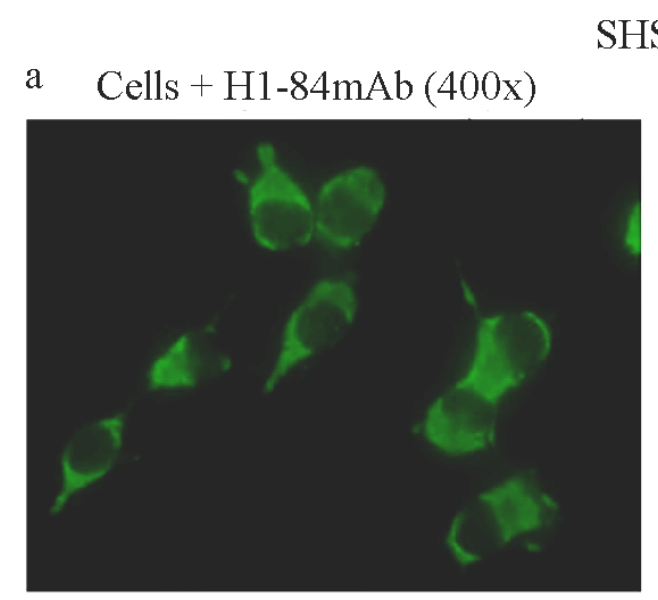

SHSY5Y cells

b Cells + isotypic antibody

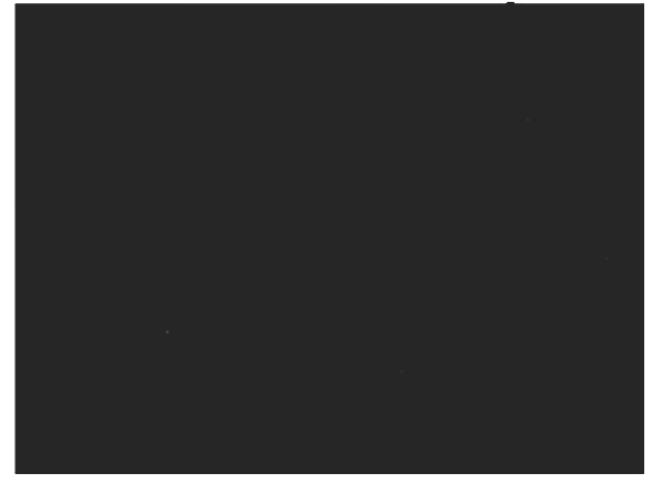

Rat primary neuroastrocytes

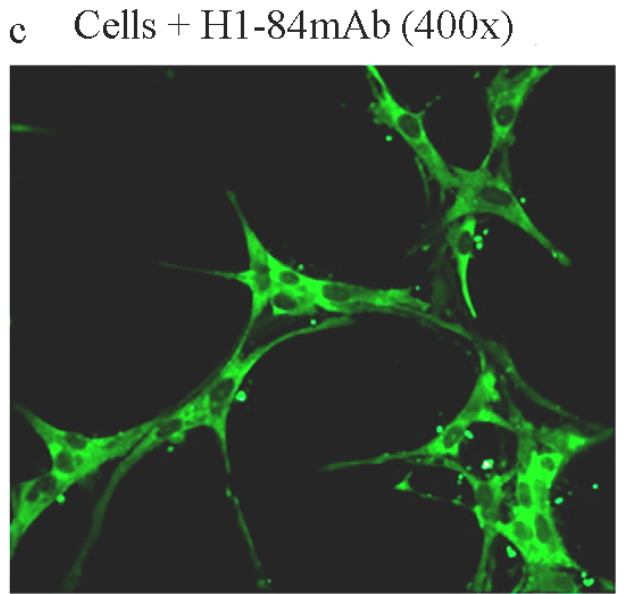

d Cells + isotypic antibody

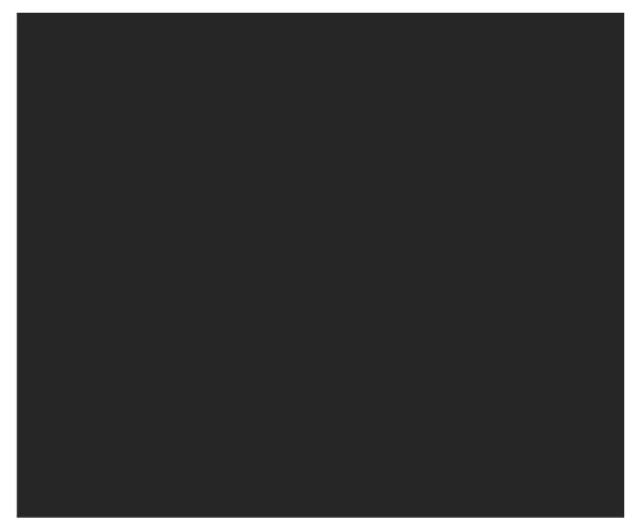

Fig. 2. H1-84mAb cross-binds to neural cells as demonstrated by immunofluorescence staining: a and c) H1-84mAb stains the cytoplasm of neural cells; $b$ and d) control isotype antibody does not bind to neural cells. The cells used were SHSY5Y cells ( $a$ and b) and rat primary neuroastrocytes (c and d).

of hnRNPA1 could also appear outside the neuron as an autoantigen exposed to the immune system, generating an antigenic target for the production of anti-hnRNPA1 autoantibodies [18, 19]. Douglas et al. injected antihnRNPAl antibodies into the EAE (experimental autoimmune encephalomyelitis) mice and found that it aggravated the clinical symptoms of multiple sclerosis, resulting in neurodegenerative lesions in the ventral spinocerebellar tract of the spinal cord and deep white matter of the central nervous system [20]. Levin et al. showed that anti-hnRNPA1 antibodies can cause neuronal damage, leading to neurodegenerative changes in the central nervous system [21]. Our previous study demonstrated that $\mathrm{H} 1-84 \mathrm{mAb}$ not only binds to hnRNPA1 in the rat brain tissue, but also in the human neuroblastoma SHSY5Y cell line. In this study, we observed that H1$84 \mathrm{mAb}$ interacted with proteins in the cytoplasm of SHSY5Y cell (Fig. 2), which could lead to the damage of neural cells (Fig. 4).

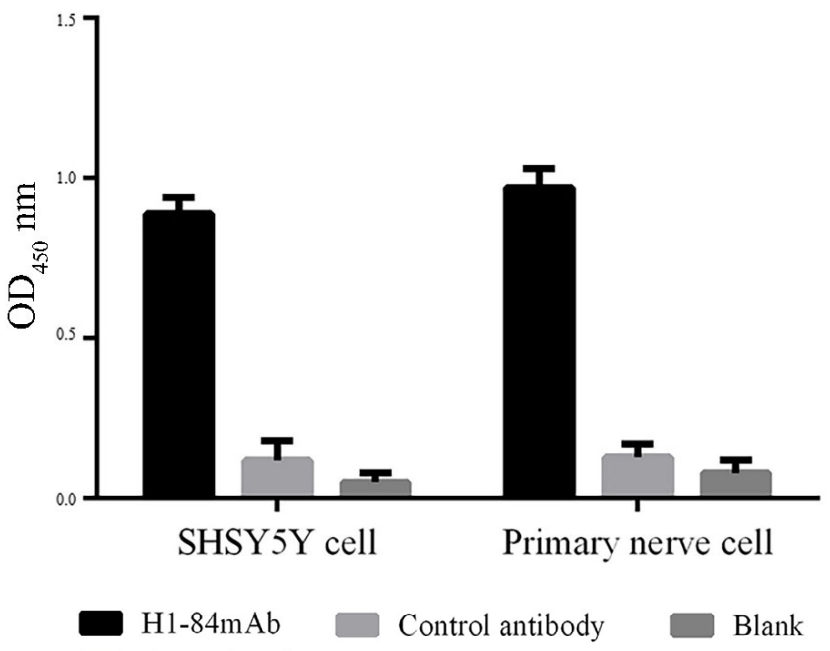

Fig. 3. H1-84mAb cross-binds to neural cells as demonstrated by cell ELISA. 
SHSY5Y cells

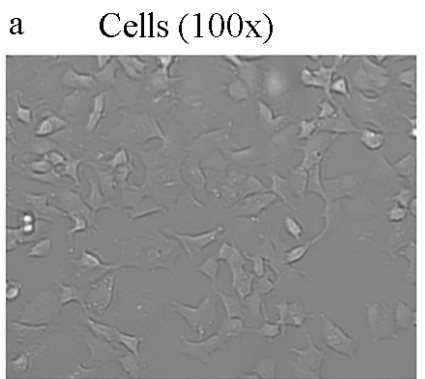

b Cells + isotypic antibody

c Cells $+\mathrm{H} 1-84 \mathrm{mAb}$
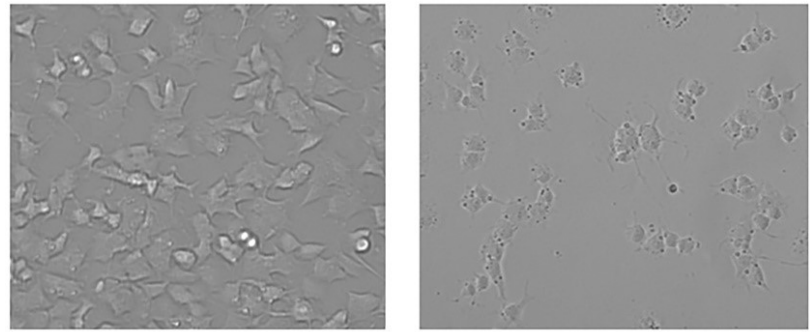

Rat primary neuroastrocytes

d Cells (100x)

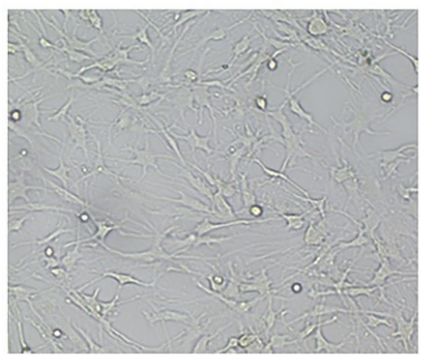

e Cells + isotypic antibody

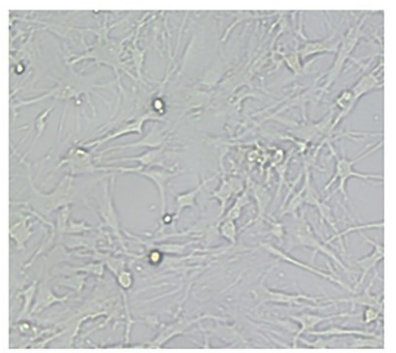

f Cells $+\mathrm{H} 1-84 \mathrm{mAb}$

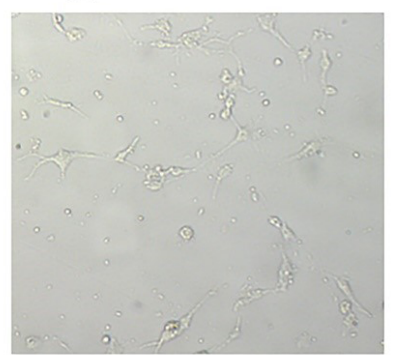

Fig. 4. $\mathrm{H} 1-84 \mathrm{mAb}$ mediated neuronal cell damage. a and d) Untreated cells (control); $\mathrm{b}$ and e) cells treated with the isotypic antibody; $c$ and f) cells treated with H1-84mAb.

a

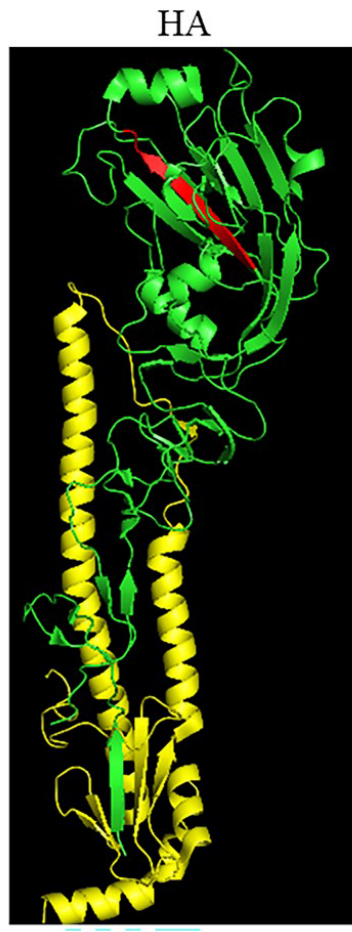

$\mathrm{b}$

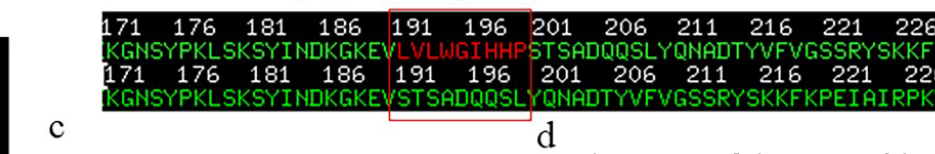

HA1 containing 9 peptide

HA1

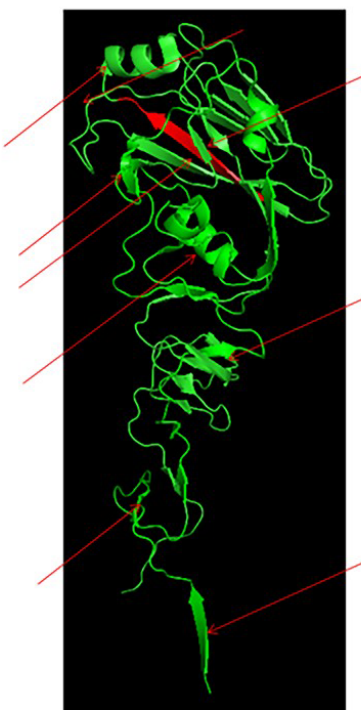

The HAl of the 9 peptide

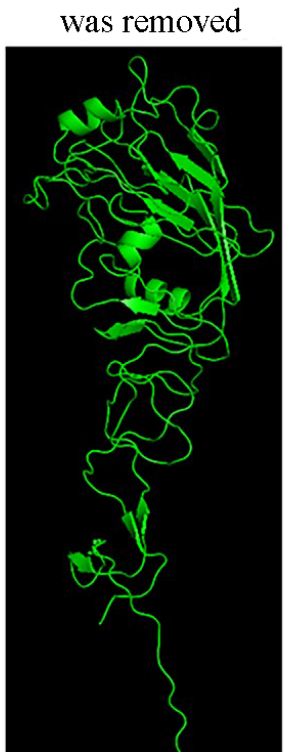

Fig. 5. Removal of the HA191/199 region changes the structure of the HA head. a) Location of the HA191/199 region (9-mer linear epitope) in the HA head. b) Fragment of the HA sequence before and after removal of the 191/199 region. $\mathrm{c}$ and d) The structure of the HA head before and after removal of the HA191/199 region, respectively. 
a

Five antigenic sites on the head of HAl

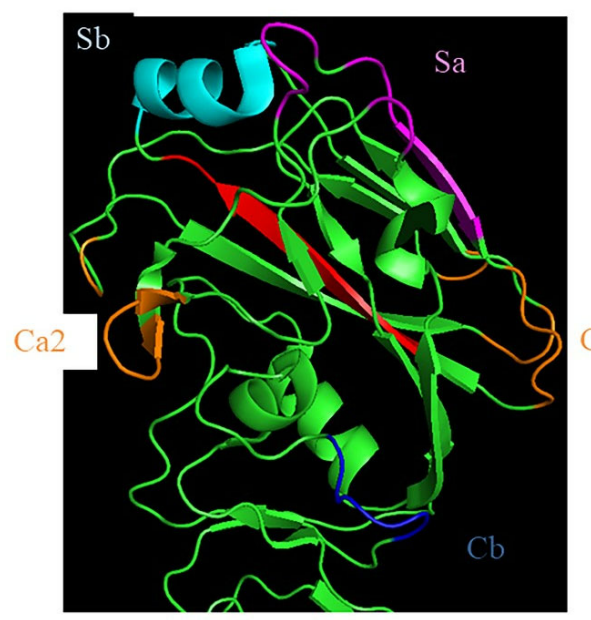

b

The HAl antigen sites after the 9 peptide was removed

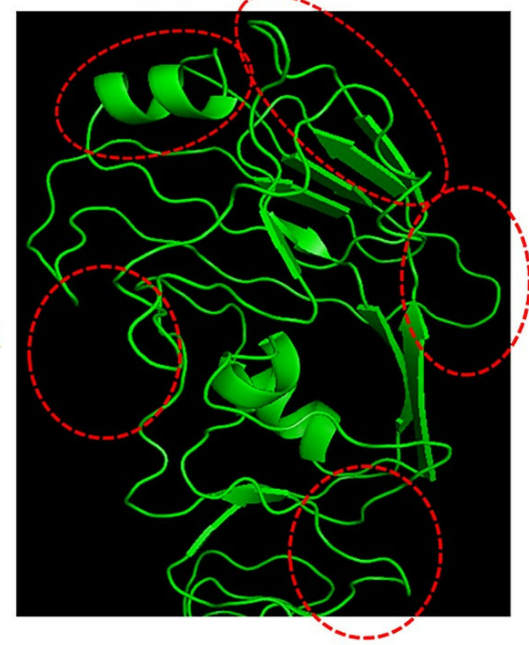

Fig. 6. Enlarged view of the antigenic sites in the HA head before (a) and after (b) removal of the 191/199 region.

Influenza virus HA is a common target for vaccine development [22, 23]. HA is a trimer formed by three noncovalently bound HA monomers, each consisting of the head and stem domains. HA monomers can be cleaved into HA1 (16-345 a.a.) and HA2 (346-519 a.a.) by the host cell proteases. HA1 is a globular head mainly composed of $\beta$-strands [24]. HAl contains the receptor-binding site and five major antigenic sites ( $\mathrm{Sa}, \mathrm{Sb}, \mathrm{Ca} 1, \mathrm{Ca} 2$, and $\mathrm{Cb}$ ) representing an antigen-determining cluster for neutralizing antibody recognition [23]. Kuenstling et al. used a prokaryotic expression system to express the HA head fragments HA11-326 and HA153-269. Both fragments induced production of neutralizing antibodies, but only HA11-326 (which can form trimers) protected the mice from the live H1N1 virus [25]. It was suggested that the whole region of the HA head affects the vaccine efficacy.

In this study, we used computer simulation and prediction methods to verify that the HA191/199 region of the influenza virus HA identified by $\mathrm{H} 1-84 \mathrm{mAb}$ is located in the HA head and is formed by $\beta$-strands. Removal of this regions results in the disturbance of the multistranded reverse $\beta$-strand structure of the HA head, as well as alterations in the structure of the antigenic $\mathrm{Sa}$ and $\mathrm{Sb}$ sites near the receptor-binding pockets, the $\mathrm{Ca} 1$ and $\mathrm{Ca} 2$ sites located at the subunit interface, and the $\mathrm{Cb}$ site in the vestigial esterase domain, thus affecting the immune effect of influenza A vaccine [26]. Therefore, the HA191/199 region cannot be removed from the HA molecule.

Poh et al. introduced single and multiple substitutions of the amino acid residues at positions 148, 150 and 183, 186 and 188 in the full-length HA protein, which improved the protective effect of the H9N2 vaccine [27]. It is possible that the in vitro site-directed mutagenesis can improve the immunogenic effect of the influenza A virus
HA. We previously found that $\mathrm{H} 1-84 \mathrm{mAb}$ recognizes the core residues V192, L193, W194, I196, and P199 in the HA191/199 region [10]. Therefore, it is feasible to develop a safe and efficient influenza A vaccine by removing these residues via in vitro site-directed mutagenesis.

In conclusion, we found that $\mathrm{H} 1-84 \mathrm{mAb}$ against influenza virus HA not only interacts with the functional areas of the protein (HA191/199 region), but also binds to neural cells and mediates their damage, thus playing an important role in the induction of adverse reactions of the nervous system after flu vaccination. Since the HA191/199 region cannot be deleted directly, it has to be altered through site-directed mutagenesis in order to further improve the safety of the H1N1 vaccine.

Funding. This work was supported by the Incubation Fund Program of Shaanxi Provincial People's Hospital (no. 2019YXQ-12), Key Research and Development Program of Shaanxi (no. 2021ZDLSF01-03), and National Key Research and Development Program of China (no. 2016YFD0500700).

Ethics declarations. The authors declare no conflicts of interest in financial or any other sphere. This article does not contain description of studies with human participants or animals performed by any of the authors.

Supplementary information. The online version contains supplementary material available at https://doi.org/ 10.1134/S0006297921110109.

\section{REFERENCES}

1. Fan, H. T., Walker, A. P., Carrique, L., Keown, J. R., Serna, M. I., et al. (2019) Structures of influenza A virus RNA polymerase offer insight into viral genome replica- 
tion, Nature, 573, 287-290, doi: 10.1038/s41586-0191530-7.

2. Xiao, J., Shiu, E. Y. C., Gao, H., Wong, J. Y., Fong, M. W., et al. (2020) Nonpharmaceutical measures for pandemic influenza in nonhealthcare settings-personal protective and environmental measures, Emerging Infect. Dis., 26, 967975, doi: 10.3201/eid2605.190994.

3. Kazakova, A., Kakkola, L., Ziegler, T., Syrjänen, R., Päkkilä, H., et al. (2020) Pandemic influenza A(H1N1pdm09) vaccine induced high levels of influenza-specific IgG and IgM antibodies as analyzed by enzyme immunoassay and dualmode multiplex microarray immunoassay methods, Vaccine, 38, 1933-1942, doi: 10.1016/j.vaccine.2020.01.022.

4. Liang, X. F., Wang, H. Q., Wang, J. Z., Fang, H. H., Wu, J., et al. (2010) Safety and immunogenicity of 2009 pandemic influenza A H1N1 vaccines in China: a multicentre, double-blind, randomised, placebo-controlled trial, Lancet, 375, 56-66, doi: 10.1586/erv.10.23.

5. Sanz, F. R., Martín, A. L., Molina-Guarneros, J. A., Jimeno, B. N., and García, O. P. (2019) Guillain-Barré syndrome and influenza vaccines: current evidence, Rev. Esp. Quimioter, 32, 288-295.

6. Ding, H. L., and Yan, H. Y. (2015) Retrospective clinical analysis of 21 cases of acute disseminated encephalomyelitis in children, Chin. Pract. Med., 10, 66-67.

7. Sarkanen, T. O., Alakuijala, A. P. E., Dauvilliers, Y. A., and Partinen, M. M. (2018) Incidence of narcolepsy after H1N1 influenza and vaccinations: systematic review and meta-analysis, Sleep Med. Rev., 38, 177-186, doi: 10.1016/ j.smrv.2017.06.006.

8. Forssman, J. (1911) Herstellung hochwertiger spezifischer Schafhamonysine ohne Verwendung von Schafblut. Ein Beitrag zur Lehre von heterologer Antikörpebildung [in German], Biochem. Z., 37, 78-115.

9. Ahmed, S. S., Volkmuth, W., Duca, J., Corti, L., Pallaoro, M., et al. (2015) Antibodies to influenza nucleoprotein cross-react with human hypocretin receptor 2, Sci. Transl. Med., 7, 1-14, doi: 10.1126/scitranslmed.aab2354.

10. Guo, C. Y., Zhang, H. X., Zhang, J. J., Sun, L. J., Li, H. J., et al. (2019) Localization analysis of heterophilic antigen epitopes of H1N1 influenza virus hemagglutinin, Virol. Sin., 34, 306-314, doi: 10.1007/s12250-019-00100-9.

11. Guo, C. Y., Tang, Y. G., Qi, Z. L., Liu, Y., Zhao, X. R., et al. (2015) Development and characterization of a panel of cross-reactive monoclonal antibodies generated using H1N1 influenza virus, Immunobiology, 220, 941-946, doi: 10.1016/j.imbio.2015.02.002.

12. Guo, C. Y., Sun, L. J., Hao, S. P., Huang, X. Y., Hu, H. Y., et al. (2020) Monoclonal antibody against H1N1 influenza virus hemagglutinin cross reacts with hnRNPA1 and hnRNPA2/B1, Mol. Med. Rep., 22, 3969-3975, doi: 10.3892/ mmr.2020.11494.

13. Lee, S. M., Dunnavant, F. D., Jang, H., Zunt, J., and Levin, M. C. (2006) Autoantibodies that recognize functional domains of hnRNPA1 implicate molecular mimicry in the pathogenesis of neurological disease, Neurosci. Lett., 401, 188-193, doi: 10.1016/j.neulet.2006.03.016.

14. Zhou, S. R., and Hou, X. D. (1984) Immune complexes and neurological diseases, Foreign Med. Int. Med., 11, 430-433.

15. Ng, Y. P., Yip, T. F., Peiris, J. S. M., Ip, N. Y., and Lee, S. M. Y. (2018) Avian influenza A H7N9 virus infects human astrocytes and neuronal cells and induces inflam- matory immune responses, J. Neurovirol., 24, 752-760, doi: 10.1007/s13365-018-0659-8.

16. Hallberg, P., Smedje, H., Eriksson, N., Kohnke, H., Daniilidou, M., et al. (2019) Pandemrix-induced narcolepsy is associated with genes related to immunity and neuronal survival, EBioMedicine, 40, 595-604, doi: 10.1016/ j.ebiom.2019.01.041.

17. Kolehmainen, A., Rossi, M., Stupak, J., Li, J., Gilbert, M., and Wakarchuk, W. (2019) Genetics behind the biosynthesis of nonulosonic acid-containing lipooligosaccharides in Campylobacter coli, J. Bacteriol., 201, e00759-18, doi: 10.1128/JB.00759-18.

18. Libner, C. D., Salapa, H. E., Hutchinson, C., Lee, S., and Levin, M. C. (2020) Antibodies to the RNA binding protein heterogeneous nuclear ribonucleoprotein A1 contribute to neuronal cell loss in an animal model of multiple sclerosis, J. Comp. Neurol., 528, 1704-1724, doi: 10.1002/cne.24845.

19. Salapa, H. E., Libner, C. D., and Levin, M. C. (2020) Dysfunctional RNA-binding protein biology and neurodegeneration in experimental autoimmune encephalomyelitis in female mice, J. Neurosci. Res., 98, 704-717, doi: 10.1002/jnr.24554.

20. Douglas, J. N., Gardner, L. A., Salapa, H. E., Lalor, S. J., Lee, S., et al. (2016) Antibodies to the RNA-binding protein hnRNPA1 contribute to neurodegeneration in a model of central nervous system autoimmune inflammatory disease, J. Neuroinflammation, 13, 178, doi: 10.1186/s12974016-0647-y.

21. Levin, M. C., Lee, S., Gardner, L. A., Shin, Y., Douglas, J. N., and Salapa, H. (2017) Autoantibodies to heterogeneous nuclear ribonuclear protein A1 (hnRNPA1) cause altered "ribostasis" and neurodegeneration; the legacy of HAM/TSP as a model of progressive multiple sclerosis, J. Neuroimmunol., 304, 56-62, doi: 10.1016/j.jneuroim. 2016.07.005.

22. Islam, S., Zhou, F., Lartey, S., Mohn, K. G. I., Krammer, F., (2019) Functional immune response to influenza $\mathrm{H} 1 \mathrm{~N} 1$ in children and adults after live attenuated influenza virus vaccination, Scand. J. Immunol., 90, e12801, doi: 10.1111/sji.12801.

23. Sangster, M. Y., Nguyen, P. Q. T., and Topham, D. J. (2019) Role of memory B cells in hemagglutinin-specific antibody production following human influenza A virus infection, Pathogens, 8, 167, doi: 10.3390/pathogens8040167.

24. Xu, R., Ekiert, D. C., Krause, J. C., Hai, R., Crowe, J. E., and Wilson, I. A. (2019) Structural basis of preexisting immunity to the $2009 \mathrm{H} 1 \mathrm{~N} 1$ pandemic influenza virus, Science, 328, 357-360, doi: 10.1126/science.1186430.

25. Kuenstling, T. E., Sambol, A. R., Hinrichs, S. H., and Larson, M. A. (2018) Oligomerization of bacterially expressed $\mathrm{H} 1 \mathrm{~N} 1$ recombinant hemagglutinin contributes to protection against viral challenge, Sci. Rep., 8, 11856, doi: 10.1038/s41598-018-30079-4.

26. Zolotarova, O., Budzanivska, I., Leibenko, L., Radchenko, L., and Mironenko, A. (2019) Antigenic site variation in the hemagglutinin of pandemic influenza A(H1N1)pdm09 viruses between 2009-2017 in Ukraine, Pathogens, 8, 194, doi: 10.3390/pathogens8040194.

27. Poh, Z. W., Wang, Z., Kumar, S. R., Yong, H. Y., and Prabakaran, M. (2020) Modification of neutralizing epitopes of hemagglutinin for the development of broadly protective H9N2 vaccine, Vaccine, 38, 1286-1290, doi: 10.1016/j.vaccine.2019.11.080. 